\title{
Analysis of Industrial Structure of Gansu Province Based on IO-SDA Method*
}

\author{
Yan Han \\ School of Economics \& Management \\ Lanzhou Jiaotong University \\ Lanzhou, China 730070 \\ Laboratory of Economic Geography and Regional Development \\ Institute of Geographic Sciences and Natural Resources Research \\ Beijing, China 100101
}

\author{
Heng Li \\ School of Economics \& Management \\ Lanzhou Jiaotong University \\ Lanzhou, China 730070
}

\author{
Yuting Zhang \\ School of Economics \& Management \\ Lanzhou Jiaotong University \\ Lanzhou, China 730070
}

\begin{abstract}
Based on the IO-SDA economic growth factor model, the Gansu Provincial Input-output Table from 2002 to 2012 was used to analyze the industrial structure related issues. Studies have shown that traditional industries such as extractive industries, petroleum and petrochemical industries, and textile industries are still the leading industries for economic development in Gansu Province; the dependence of the primary and secondary industries on the tertiary industry is rising, but the development is relatively slow. The modern service industry has a limited role in promoting economic development; consumer demand and fixed capital formation are the primary factors driving the industrial development of Gansu Province. Therefore, it is necessary to optimize the industrial structure, develop leading industries and characteristic industries, and develop modern industrial clusters with outstanding advantages to realize the adjustment and optimization of the industrial structure of Gansu Province.
\end{abstract}

Keywords-IO-SDA model; industrial structure; dynamic mechanism; Gansu Province

\section{INTRODUCTION}

Industrial structure is not only the result of regional economic growth in the past, but also the basis of economic growth in the new stage, which has a profound impact on regional economic development [1] [2]. The level and rationality of industrial structure even determine the economic quality, strength, growth rate and stability of the region [3]. As the eternal theme of economic growth, industrial structure is closely related to economic growth [4]. Industrial structure adjustment is not only one of the important topics in economic research, but also a major problem to be solved in the process of industrial

*Funds: Ministry of Education Humanities and Social Sciences Research Project (Project No.: 18YJCZH044); National Natural Science Foundation of China (Project No.: 41401653). development in various countries. By combing the existing literature, domestic and foreign scholars on the industria structure of the relevant research mainly involves three aspects.

The first is the study on the causes of the evolution of industrial structure. Parrinello [5] believes that the driving factors of industrial structure evolution are influenced by technology, international trade and different demand structures among industries. Desmet K [6] believes that the overall transformation and upgrading of industrial structure is realized under the alternating action of scientific and technological innovation and leading industry. The transfer of factors from the low productivity growth sector to the high productivity growth sector has also promoted economic growth and the improvement of total factor productivity. Zhang Cuiju [7] analyzed the factors that affect and determine the change of provincial industrial structure in China from the point of view of foreign direct investment, fixed asset investment, consumption structure, urbanization, technological progress and so on. The second is the research on the path of industrial structure adjustment and upgrading. Tian [8] attaches importance to the reconstruction of industrial layout and believes that industrial transformation is the process of transformation from the layout structure of traditional industry to the new pattern of industrial layout of high-tech industry or service industry.

According to the research, an important fact accompanied by the optimization and upgrading of the industrial structure is the transfer of labor factors from the primary industry to the secondary and tertiary industries. Therefore, L.Brandt et al [9] and R.Dekle et al [10] use the share of labor force in the primary industry to measure the change of static industrial structure. Chen Qiang [11] believes that the path research on industrial transformation and upgrading has gradually shifted from the upgrading of 
the industrial value chain to the industrial repositioning based on comparative advantage or the construction of industrial system based on technological progress from the perspective of the whole economy. No matter which angle requires the marketization as the core of the system choice, the real economy as the focus of the industrial choice. The third is the study of the relationship between industrial structure and economic growth. Michael Peneder [12] found that there is a mutually promoting relationship between accelerated economic growth and the evolution of industrial structure in the process of structural transformation. Zhou X $Y$ et al. [13] believe that the rationalization of industrial structure reflects the coordinated development of inputoutput structure among different industries, which can significantly affect the allocation and use of factors, and then affect economic growth. Kao Ai-hsiung [14] pointed out that economic inefficiency has led to a slowdown in China's economic growth in recent years. $\mathrm{Li} \mathrm{Cun} \mathrm{Pu}$, he Jing [15] used nonlinear smooth transformation model to study the nonlinear influence of industrial structure upgrading. The results show that there is a nonlinear relationship between industrial structure upgrading and economic growth, industrial structure and unemployment.

The above research provides a lot of experience and methodological guidance for the discussion of industrial structure-related problems, but there are still some improvements. Firstly, from the perspective of research category, most of the literature takes the country or city as the research object, and discusses the related problems of its industrial structure, but there is little research on a province, especially the underdeveloped provinces. With the promotion of "Belt and Road Initiative" strategy, it is particularly important to focus on the industrial development of the relevant provinces along the route. Secondly, from the perspective of research methods, the current research on industrial structure in the use of quantitative model methods is still relatively single and weak, the research content is also relatively single, the lack of realistic data to support the conclusion.

At present, there are relatively many theoretical studies on the current situation and existing problems of industrial structure in Gansu Province. However, few literatures deeply analyze the leading industries, characteristic industries and the factors affecting the development of industrial structure in Gansu Province through the IO-SDA economic growth factor model. In view of this, this paper is based on the economic development of Gansu Province, takes the industrial structure as the research angle, uses the IO-SDA method, uses the input-output table of Gansu Province from 2002 to 2012, analyzes the industrial structure of Gansu Province and puts forward the relevant policy suggestions. It is hoped that it can provide theoretical explanation and decision support for the optimization of industrial structure and great-leap-forward economic development in Gansu Province.

\section{RESEARCH Methods AND DATA PROCESSING}

\section{A. Research Methods}

\section{1) Influence coefficient:}

The influence coefficient reflects the degree of demand spread to each department of the national economy when an additional unit is added to the final use of a certain department of the national economy, and the calculation formula is as follows.

The influence coefficient of a department:

$$
F_{j}=\frac{\frac{1}{n} \sum b_{i j}}{\frac{1}{n^{2}} \sum \sum b_{i j}}=\frac{\sum b_{i j}}{\frac{1}{n} \sum \sum b_{i j}}
$$

Among them, $b_{i j}$ is the complete consumption coefficient of the $\mathrm{j}$ sector to the $\mathrm{i}$ sector.

When the influence coefficient of a sector is greater than (less than) 1, it indicates that the spread impact of production in that sector on other sectors is higher than (lower than) the average level of social impact (that is, the average impact of each sector).

The greater the coefficient of influence, the greater the pulling effect of this sector on other departments.

\section{2) Induction coefficient:}

The sensitivity coefficient reflects the degree of demand induction that a certain sector receives when each department of the national economy is added to the final use of a unit, that is, the output that the department provides for the production of other departments. The calculation formula is as follows.

The sensitivity coefficient of a department:

$$
E_{i}=\frac{\frac{1}{n} \sum k_{i j}}{\frac{1}{n^{2}} \sum \sum k_{i j}}=\frac{\sum k_{i j}}{\frac{1}{n} \sum \sum k_{i j}}
$$

Among them, $k_{i j}$ is the complete distribution coefficient from sector i to sector $\mathrm{j}$.

When the sensitivity coefficient of a certain department is greater than (less than) 1, the greater the sensitivity coefficient of the department is higher than (lower than) the social average sensitivity level (that is, the average induction degree of each department).

It shows that the greater the role of this sector in promoting the national economy.

The higher the sensitivity coefficient, the more the basic industry and bottleneck industry will be.

3) Composite index of industrial linkages:

In his book Economic Development Strategy, American economist Hershman puts forward the "correlation 
benchmark" for the selection of leading industries, which indicates that the industries with strong relevance should be chosen as the leading industries [16-17]. The leading industry is the engine of regional economic growth and the key to the adjustment of regional economic structure [18].

According to the Hershman benchmark, we use the industrial correlation composite index as the benchmark for the choice of leading industries. The comprehensive index of industrial correlation is the average of influence coefficient and induction coefficient.

The leading industry should choose the industry with greater influence coefficient and induction coefficient, so only the industry with large industrial correlation index can promote the development of other industries.

\section{4) IO-SDA model:}

The input-output model method was founded by Leontief (Wassily Leontief), a famous mathematical economist, in the 1930s. It is a widely used economic quantitative analysis [19].

SDA (structural decomposition analysis) model is widely used in structural analysis of complex economic problems under the influence of multiple factors [20] [21]. Through a multi-sector comparative analysis of the changes of output in the input-output table in different periods, it decomposes the change of output into the sum of the changes of various influencing factors, and calculates the contribution of each change of influencing factors to the change of total output. The theoretical basis of the "decomposition model of influencing factors of output change" constructed in this paper is Keynesian theory, which holds that the level of production and employment is determined by the level of total demand and is reflected in the input-output theory. It is concentrated in the relationship between output and aggregate demand. The influencing factors causing the growth of total output can be divided into the increase of final demand and the change of Leontief inverse matrix, and the final demand is composed of final consumption, total capital formation and net export. In this paper, the following SDA model is constructed step by step.

For Leontief's inverse input-output model, there is an identity:

$$
X=(I-A)^{-1} F
$$

Among them, $\mathrm{X}$ is the total output column vector of each industrial sector, $\mathrm{F}$ is the final total demand column vector of each industrial sector, and $(I-A)^{-1}$ is called Leontief inverse matrix.

If subscript 0 and 1 are used to represent the base period and the reporting period respectively, so that $B=(I-A)^{-1}$, the output vector of each industrial sector in the base period is $X_{0}=B_{0} F_{0}$, and the output vector of each industrial sector in the reporting period is $X_{1}=B_{1} F_{1}$.
The changes in the total output of each industry in the two periods (column vector) are as follows:

$$
\Delta X=(\Delta B) F_{0}+B_{0}(\Delta F)+(\Delta B)(\Delta F)
$$

By the same token:

$$
\Delta X=(\Delta B) F_{1}+B_{1}(\Delta F)+(\Delta B)(\Delta F)
$$

In formula (2.3) and formula (2.4), $(\Delta B) F_{0}$ or $(\Delta B) F_{1}$ represents the total output change caused by the change of input-output coefficient when the final total demand $F$ is constant.

It is called the effect of technological change; $B_{0}(\Delta F)$ or $B_{1}(\Delta F)$ refers to the total output change caused by the change of final demand when the input-output coefficient B remains unchanged. It is called final demand change effect; $(\Delta B)(\Delta F)$ refers to the total output change caused by the simultaneous change of final total demand $\mathrm{F}$ and inputoutput coefficient $\mathrm{B}$, which is called interaction effect.

Because the analysis of interaction response is difficult the weighted average decomposition method is usually used to decompose the interaction effect into the technology change effect and the final demand change effect.

Multiply the two sides of the formula (2.3) and (2.4) by $1 / 2$ and add them to:

$$
\Delta X=\frac{1}{2} \Delta B\left(F_{1}+F_{0}\right)+\frac{1}{2}\left(B_{1}+B_{0}\right) \Delta F
$$

$$
\frac{1}{2} \Delta B\left(F_{1}+F_{0}\right)
$$
is the technology change effect, and

$$
\frac{1}{2}\left(B_{1}+B_{0}\right) \Delta F
$$

$$
\text { is the final demand change effect. }
$$

The final demand vector $\mathrm{F}$ can be further divided into three parts: resident consumption column vector $\mathrm{C}$, fixed capital formation variation column vector $G$ and net export column vector $\mathrm{N}$.

Similarly, the change of final demand can be divided into the sum of the changes of the above three sectors, that is $\Delta F=\Delta C+\Delta G+\Delta N$

By bringing in the above formula, the change in total output can be divided into the sum of the following four changes:

$$
\Delta X_{A}=\frac{1}{2}(\Delta B)\left(F_{1}+F_{0}\right)
$$

technological change on the change of total output

$$
\Delta X_{C}=\frac{1}{2}\left(B_{1}+B_{0}\right) \Delta C
$$

: The influence of the change of resident consumption on the change of total output 


$$
\Delta X_{G}=\frac{1}{2}\left(B_{1}+B_{0}\right) \Delta G
$$

: The influence of the change of fixed Capital formation on the change of total output

$$
\Delta X_{N}=\frac{1}{2}\left(B_{1}+B_{0}\right) \Delta N
$$

: The influence of the change of Import and Export on the change of total output

That is, $\Delta X=\Delta X_{A}+\Delta X_{C}+\Delta X_{G}+\Delta X_{N}$. Through the "decomposition model of influencing factors of output change", the total output change of each industrial sector is divided into four images: technological change, household consumption, fixed capital formation and net export. As for the amount of change in the response factor, by dividing the output change affected by each factor by the total output of the corresponding department in the base period, the influence of the factors decomposed by the "speed of output change factor decomposition model" on the change rate of sector output can be obtained.

\section{B. Data Sources and Processing}

In order to make a comprehensive analysis of the industrial structure of Gansu Province, this paper compares the departmental classification codes and explanations of the input-output table of Gansu Province from 2002 to 2012, and makes reference to the National Economic Industry Classification and the International Standard Industrial Classification. The three input-output tables are organized into 29 departments of the same caliber, and the classification and code of the departments are shown in "Table I" below.

\begin{tabular}{|c|c|}
\hline Code & Industrial sector \\
\hline 1 & Agricultural, forestry, animal husbandry and fishing products and services. \\
\hline 2 & Mining industry. \\
\hline 3 & Food and tobacco. \\
\hline 4 & Textile products. \\
\hline 5 & Textile and clothing manufacturing industry. \\
\hline 6 & Wood processing and furniture. \\
\hline 7 & Papermaking, printing, stationery and sporting goods. \\
\hline 8 & Petrochemical industry. \\
\hline 9 & Non-metallic mineral products. \\
\hline 10 & Metal smelting and Calendering products. \\
\hline 11 & Metalware. \\
\hline 12 & General and special equipment manufacturing industry. \\
\hline 13 & Transportation equipment. \\
\hline 14 & Electrical machinery and equipment. \\
\hline 15 & Electronic equipment manufacturing industry. \\
\hline 16 & Instruments and Apparatus. \\
\hline 17 & Other manufacturing industries. \\
\hline 18 & Production and supply of electricity and heat. \\
\hline 19 & Gas production and supply. \\
\hline 20 & Production and supply of water. \\
\hline 21 & Architecture \\
\hline 22 & Wholesale and retail. \\
\hline 23 & Transportation, warehousing and postal services. \\
\hline 24 & Accommodation and catering. \\
\hline 25 & Scientific research and technology services. \\
\hline 26 & Finance. \\
\hline 27 & Real estate. \\
\hline 28 & Other services. \\
\hline 29 & Public Management and Social Organization \\
\hline
\end{tabular}

TABLE I. INDUSTRY SECTOR AdJUSTMENT TABLE 


\section{ANALYSIS ON THE EVOLUTION OF INDUSTRIAL STRUCTURE AND ITS MOTIVATION}

\section{A. Analysis of the Present Situation of the Development of Industrial Structure}

From the perspective of the proportion of the three industries in GDP, between 2002 and 2012, the proportion of the first industry in Gansu Province decreased from $17.49 \%$ to $13.75 \%$, while the second industry and the third industry accounted for about $45 \%$ and $40 \%$, respectively. The secondary industry still has an advantage. Since 2014, the proportion of the third industry has always been higher than that of the second industry, gradually reaching more than $50 \%$. In recent years, the economic development of Gansu Province has been greatly improved, and the industrial structure has also tended to be improved. In the past 16 years from 2002 to 2017, the added value of the tertiary industry increased from 51.483 billion yuan to 403.836 billion yuan, an increase of about sevenfold, and the economic structure showed a "trinity" pattern.

\section{B. Analysis of Industrial Relational Degree}

Generally speaking, the industrial sector with large influence coefficient has greater radiation capacity to social production, while the industrial sector with higher induction coefficient plays a greater role in restricting economic development [22] [23] [24] [25] [26]. When the influence coefficient and induction coefficient of an industrial sector are large, the industrial sector plays an important role in economic development [27]. The coefficients of influence and sensitivity calculated using the 2002-2012 input-output table is shown in "Table II".

TABLE II. Influential COEFFicient AND SENSITIVITy COEFFICIENT OF EACH DEPARTMENT FROM 2002 TO 2012

\begin{tabular}{|c|c|c|c|c|c|c|}
\hline \multirow{2}{*}{ Code } & \multicolumn{3}{|c|}{ Influential coefficient } & \multicolumn{3}{|c|}{ Sensitivity coefficient } \\
\hline & 2002 & 2007 & 2012 & 2002 & 2007 & 2012 \\
\hline 1 & 0.8210 & 0.8724 & 0.8065 & 1.0044 & 1.0031 & 1.0047 \\
\hline 2 & 1.0487 & 1.0990 & 1.0176 & 1.0158 & 1.0073 & 1.0045 \\
\hline 3 & 1.0904 & 1.0497 & 1.0036 & 0.9978 & 0.9988 & 0.9999 \\
\hline 4 & 1.1637 & 1.1421 & 1.0995 & 0.9960 & 0.9965 & 0.9976 \\
\hline 5 & 1.2654 & 1.1846 & 1.1288 & 0.9935 & 0.9979 & 0.9969 \\
\hline 6 & 1.1858 & 1.1084 & 1.0131 & 0.9955 & 0.9974 & 0.9997 \\
\hline 7 & 1.0784 & 1.0607 & 1.1423 & 0.9981 & 0.9985 & 0.9965 \\
\hline 8 & 1.1737 & 1.1837 & 1.1202 & 1.0957 & 1.0882 & 1.0897 \\
\hline 9 & 1.0748 & 1.1033 & 1.1112 & 0.9982 & 0.9975 & 0.9973 \\
\hline 10 & 1.0785 & 1.1091 & 1.3124 & 0.9981 & 0.9973 & 0.9924 \\
\hline 11 & 1.2777 & 1.3184 & 1.2107 & 0.9932 & 0.9922 & 0.9949 \\
\hline 12 & 1.1552 & 1.2779 & 1.2280 & 1.0962 & 1.0957 & 1.0871 \\
\hline 13 & 1.2436 & 1.2956 & 1.2558 & 0.9941 & 0.9928 & 0.9938 \\
\hline 14 & 1.7923 & 1.1002 & 1.3875 & 0.9807 & 0.9976 & 0.9905 \\
\hline 15 & 1.0680 & 1.0458 & 1.0113 & 0.9983 & 0.9964 & 0.9973 \\
\hline 16 & 1.1404 & 1.0424 & 1.0505 & 0.9966 & 0.9990 & 0.9988 \\
\hline 17 & 0.4031 & 0.9065 & 1.3271 & 1.0146 & 1.0023 & 0.9920 \\
\hline 18 & 0.7404 & 0.7947 & 0.8738 & 1.0063 & 1.0050 & 1.0031 \\
\hline 19 & 1.1161 & 1.2929 & 1.0226 & 0.9972 & 0.9929 & 0.9994 \\
\hline 20 & 0.9381 & 0.9592 & 0.7400 & 1.0015 & 1.0010 & 1.0063 \\
\hline 21 & 0.9497 & 1.0472 & 1.2162 & 1.0012 & 0.9988 & 0.9947 \\
\hline 22 & 1.0740 & 0.8309 & 0.8404 & 0.9982 & 1.0041 & 1.0039 \\
\hline 23 & 0.8934 & 0.7079 & 0.8362 & 1.0026 & 1.0071 & 1.0040 \\
\hline 24 & 0.9521 & 0.9958 & 0.8984 & 1.0012 & 1.0001 & 1.0025 \\
\hline 25 & 0.8468 & 0.7771 & 0.7235 & 1.0137 & 1.0254 & 1.0267 \\
\hline 26 & 1.0327 & 0.7847 & 0.7793 & 0.9992 & 1.0053 & 1.0054 \\
\hline 27 & 0.9003 & 0.8820 & 0.6948 & 1.0024 & 1.0029 & 1.0074 \\
\hline 28 & 1.0757 & 1.0595 & 1.0275 & 1.0061 & 1.0083 & 1.0212 \\
\hline 29 & 0.8565 & 0.8000 & 0.7448 & 1.0035 & 1.0049 & 1.0062 \\
\hline
\end{tabular}

1) Analysis of influence coefficient:

"Table II" shows that: firstly, in 2002, there were 19 sectors with an influence coefficient greater than 1; in 2007, there were 18 departments with an influence coefficient greater than 1; and in 2012, there were 19 departments with an influence coefficient greater than 1. Compared with 2002, the sectors with higher influence coefficient in 2007 and 2012 changed little, and the evolution of industrial structure was not obvious. Secondly, the influence coefficient of three years can be compared: extractive industry, textile industry, petrochemical industry, general and special equipment manufacturing industry are still the pillar industries of economic development in Gansu Province; The influence coefficient of metal products, transportation equipment, electrical machinery and equipment is still stable and maintained at a high level. Thirdly, the industries with high influence coefficient are concentrated in the secondary industry, especially the extractive industry and petrochemical industry, which are higher than the average level of social influence and have great radiation on social production, which can promote the development of other related industries. However, there is little room for the re- 
development of these industries. Therefore, on the basis of stabilizing the output of products, we should speed up technological transformation and product upgrading, and pay attention to the use of resources and environmental protection. Fourthly, the continuous extension of heavy chemical industry has led to the development of mining industry. Gansu Province is rich in mineral resources, and the radiation driving role of heavy chemical industry and machinery manufacturing industry is increasing. Fifthly, at present, the scientific research and technology industry has become a new growth point of economic development, and seizing the commanding point of the development of related industries has become an important strategy for the economic development of various countries and regions. However, from the above table, we can know that the influence level of scientific research and technology industry has declined continuously in recent years, even lower than the average social influence level, and the radiation to social production is small, which is not enough to promote the development of other related industries.

2) Analysis of induction coefficient:

"Table II" shows that: firstly, in 2002, there were 14 sectors with a sensitivity coefficient greater than 1; in 2007, there were 15 departments with a sensitivity coefficient greater than 1; and in 2012, there were 14 departments with a sensitivity coefficient greater than 1. Through the comparison, it can be seen that the industrial sectors with higher sensitivity coefficient have little change from 2002 to 2012. Secondly, comparing the data of three years, it can be seen that the induction coefficient of agriculture, forestry, animal husbandry and fishing, extractive industry, general and professional equipment manufacturing industry is significantly higher than that of other industries. Thirdly, in recent years, the dependence of the primary and secondary industries on the tertiary industry is increasing, but their development is still relatively slow. Compared with most provinces, the modern service industry in Gansu Province lags behind, and its role in promoting economic development is still limited. The sensitivity coefficients of the three traditional service industries, namely, transportation and warehousing, accommodation and catering, and wholesale and retail, are all greater than 1 , which is higher than the social average, which indicates that the industrial structure of Gansu Province has gradually evolved into a "3-2-1" pattern. But the momentum of development is slow. Fourthly, the sensitivity coefficient of scientific research and technology service industry is large, so in the future development, we should pay attention to education and scientific research, produce high-tech products, and promote the development of high-end industrial chain. Fifthly, the industries with higher sensitivity coefficient are generally directly related to the field of production, and the industries with lower sensitivity coefficient are generally closely related to life. Therefore, in the process of industrial development, priority should be given to the development of industries with high sensitivity coefficient, so as to cooperate with the development of other related industries and avoid them becoming bottleneck industries.

\section{Analysis of Leading Industries}

With reference to the industrial correlation composite index, under comprehensive consideration, this paper establishes the departments that should be upgraded and given priority to the upgrading of the industrial structure in Gansu Province, as shown in "Table III" below.

TABLE III. LEAdING INDUSTRIAL SECtors IN GANSU PROVINCE

\begin{tabular}{|c|c|}
\hline Code & Industrial sector \\
\hline 2 & Mining industry. \\
\hline 3 & Food and tobacco. \\
\hline $4 \& 5$ & Textile industry. \\
\hline 6 & Wood processing and furniture. \\
\hline 8 & Petrochemical industry. \\
\hline 11 & Metal products related industries. \\
\hline 12 & General and special equipment manufacturing industry. \\
\hline 13 & Transportation industry. \\
\hline 16 & Instruments and Apparatus. \\
\hline $19 \& 20$ & Production and supply of water and gas \\
\hline
\end{tabular}

\section{Analysis of Driving Factors of Industrial Structure Change}

Through the SDA model constructed above, we can know that the change of total output is caused by technological changes, household consumption, fixed capital formation and net export.

From the proportion, it can be inferred that the contribution of each driving factor to the industrial growth rate is positive and negative, and the positive value shows that this factor has a positive impact on the change of output, that is, under the condition that the total demand is unchanged.

Other industries have increased their input into the industry in the production process, thus increasing the output of the industry. The negative value shows that this factor has a negative impact on the change of output, that is, under the condition of constant total demand, other industries reduce the input to the industry in the production process, thus reducing the output of the industry.

Considering the significance of the results, this paper uses the SDA model to analyze the driving factors of industrial structure changes in Gansu Province from 2007 to 2012, and the results are shown in "Table IV". 
TABLE IV. CONTRIBUTION OF VARIOUS FACTORS TO THE OUTPUT GROWTH OF 29 SECTORS

\begin{tabular}{|c|c|c|c|c|c|}
\hline Industrial sector & Technological change & Resident consumption & Fixed assets formation & Net export & Annual growth rate \% \\
\hline 1 & -160.82 & 12.26 & 26.43 & -0.71 & 0.24 \\
\hline 2 & -1345.56 & 106.01 & 238.28 & -9.15 & 0.75 \\
\hline 3 & -197.77 & 15.36 & 32.61 & -0.37 & 0.5 \\
\hline 4 & -817.00 & 63.70 & 139.59 & -2.29 & 0.38 \\
\hline 5 & -1215.11 & 96.47 & 208.54 & 0.10 & 2.27 \\
\hline 6 & -4517.47 & 336.76 & 760.25 & -14.48 & 1.63 \\
\hline 7 & -1515.39 & 139.99 & 302.06 & -6.87 & 2.04 \\
\hline 8 & -345.82 & 27.19 & 60.52 & -2.44 & 0.3 \\
\hline 9 & -157.10 & 13.21 & 32.34 & -0.48 & 0.65 \\
\hline 10 & -193.98 & 15.39 & 35.56 & -2.09 & 0.33 \\
\hline 11 & -2852.03 & 212.16 & 479.55 & -13.58 & 1.08 \\
\hline 12 & -1111.83 & 86.65 & 197.46 & -6.10 & 0.77 \\
\hline 13 & -965.09 & 75.38 & 168.99 & -4.62 & 2.09 \\
\hline 14 & -1117.21 & 84.66 & 198.76 & -3.71 & 2.27 \\
\hline 15 & -1179.48 & 96.19 & 209.85 & -4.84 & 1.84 \\
\hline 16 & -10764.51 & 813.25 & 1814.19 & -41.84 & 5.19 \\
\hline 17 & -301.00 & 31.80 & 71.99 & -1.79 & 1.06 \\
\hline 18 & -691.83 & 52.90 & 118.46 & -4.63 & 0.27 \\
\hline 19 & 72.27 & 20.47 & 37.29 & -2.14 & 1.35 \\
\hline 20 & -135.17 & 29.71 & 64.26 & -2.41 & 1.02 \\
\hline 21 & -9.70 & 0.82 & 3.73 & -0.14 & 0.38 \\
\hline 22 & --28.08 & 6.01 & 12.79 & -0.66 & 0.5 \\
\hline 23 & -227.80 & 19.97 & 44.41 & -1.94 & 0.22 \\
\hline 24 & -297.38 & 23.31 & 50.74 & -1.90 & 0.24 \\
\hline 25 & -156.04 & 13.83 & 29.60 & -1.26 & 0.75 \\
\hline 26 & -438.57 & 39.21 & 85.16 & -3.37 & 0.5 \\
\hline 27 & -53.74 & 6.04 & 10.88 & -0.39 & 0.38 \\
\hline 28 & -469.49 & 47.64 & 104.98 & -3.34 & 2.27 \\
\hline 29 & -96.40 & 7.01 & 15.63 & -0.54 & 1.65 \\
\hline
\end{tabular}

From the data in "Table IV", it can be known that through the SDA weighted average method, we can get the dynamic changes of the contribution rate of various factors to the total output of 29 main sectors and the average growth rate of each industry. As can be seen from the table, the industry with the fastest average annual growth in Gansu Province from 2007 to 2012 is the instrumentation industry, with a growth rate of 519 percent, followed by electrical machinery and equipment, with a growth rate of 227 percent. Transportation equipment in heavy industry is growing rapidly.

In light industry, textile, clothing, shoes, hats, leather down and its products, papermaking, printing, stationery and sporting goods maintained a high speed of development, with a growth rate of $227 \%$ and $204 \%$, respectively. Other services and wholesale and retail sectors in the tertiary industry are growing rapidly. $227 \%$ and $50 \%$, respectively, the other sub-sectors are in a state of growth, there is no negative growth and stagnant industries.

Through quantitative analysis, it is found that: firstly, household consumption contributes the most to the output growth of the following seven product sectors: extractive industry, petrochemical industry, metal smelting and calendering industry, agriculture, general and special equipment manufacturing, and metals, production and supply of products, electricity and heat. Secondly, fixed capital formation also contributes significantly to the abovementioned product components: extractive industries, petrochemical industries, metal smelting and Calendering industries, agriculture, general and specialized equipment manufacturing, production and supply of metal products, electricity and heat. Thirdly, the effect of net export on the output change of textile and clothing manufacturing industry is positive, which is 0.10 , and the output change of the other 
28 product sectors is negative, which indicates that the lag of the development level of net export reduces the total output. Fourthly, the impact of Leontief inverse matrix change (technical change) only on the output change in the gas production and supply sector is positive, which is 72.72 . The remaining 28 sectors are negative, indicating that the lag in the level of technological development has reduced total output.

In summary, the main factors affecting the change of industrial output and driving economic growth in Gansu Province are consumer demand and fixed capital formation, and technological progress and net exports contribute little to output growth. Therefore, to enhance the economic development of Gansu Province, to promote industrial upgrading and transformation, it is necessary to speed up the improvement of technological level and promote industrial development; at the same time, open to the outside world platform to promote economic growth with the development of import and export.

\section{CONCLUSION AND RECOMMENDATIONS}

\section{A. Conclusion}

In this paper, by using the input-output table from 2002 to 2012, by using the IO-SDA economic growth factor model, the following conclusions are drawn: firstly, the leading industries in Gansu Province are extractive industry, food and tobacco industry, textile industry, wood processing and furniture industry, petrochemical industry, metal products related industry, general industry and specialty industry, production and supply of equipment manufacturing, transportation, instrumentation, water and gas. Secondly, the main factors of industrial output change and economic growth in Gansu Province are consumer demand and fixed capital formation, and technological progress and net export make little contribution to output growth. Thirdly, the economic development of Gansu Province has been greatly improved, the industrial structure has also tended to be perfect, and the economic structure has shown a "three-twoone" pattern, and the dependence of the primary and secondary industries on the tertiary industry has been increasing, but the development is relatively slow. The role of modern service industry in promoting economic development is still limited.

\section{B. Policy Recommendations}

\section{1) Path of industrial structure optimization:}

It's a must to gradually promote light industry and improve the industrial structure. Gansu Province needs to break the existing industrial pattern, give priority to the development of advanced manufacturing, resource deep processing and high-tech industries, and speed up the development of tobacco and other industries with comparative advantages. At the same time, it is necessary to vigorously develop strategic emerging industries such as electronic information, new energy and new materials, promote the coordinated development of upstream and downstream industrial chains and related industries, and promote the transformation and upgrading of the industrial structure in Gansu Province.

It's a must to speed up the development of modern service industries. The "Belt and Road Initiative" strategy will promote Gansu Province to actively undertake industrial transfer in the eastern and central regions, adjust the economic structure, optimize the industrial layout, and promote the development of modern service industries. The continuous development of the tertiary industry, such as cultural tourism, finance and insurance, e-commerce and so on, will continue to promote the development of other industries.

It's a must to expand foreign trade. With the help of the new opportunity of the westward platform, Gansu Province needs to actively carry out the work of "going out" to the west, establish business representative offices abroad, and cooperate with the ports of Central Asian countries, which will lay a solid foundation for the further development of foreign trade. On the other hand, through the establishment of Lanzhou Free Trade area in China, Lanzhou can make full use of the Qinghai-Tibet Railway and expand the economic exchanges between the Tibet market and the Middle East countries.

2) Development of leading and characteristic industries.

It's a must to actively strive for the state's policy support for the transformation of the old industrial base, and persist in using high and new technology and advanced technology to upgrade the development level of the petrochemical industry, special equipment, non-ferrous metallurgy industry, textile industry, and so on. In the petrochemical industry, around the construction of the national petrochemical industrial base and petroleum reserve base, we will vigorously promote the optimization and upgrading of the petrochemical industrial structure; in the non-ferrous metallurgical industry, we will speed up the development of the metallurgical non-ferrous industry.

It's a must to build an important metallurgical and nonferrous metal base in the country; in the light industry and textile industry, we will actively support the transformation and upgrading of existing enterprises, encourage private economic investment, and open up markets.

It's a must to give prominence to the development of agriculture with special characteristics and advantages and improve the efficiency of agricultural production. To support the construction of potato trade, industry and agriculture integrated demonstration area dominated by Dingxi, strengthen the construction of hybrid corn and other crop planting bases in Hexi Corridor, and speed up the development of traditional Chinese medicine, forest, fruit, vegetables and other industries; it is necessary to actively develop local characteristic products such as edible lilies, bitter water roses, white peaches and chrysanthemums; vigorously develop herbivorous animal husbandry and current agricultural demonstration farms; and actively promote Lanzhou Hand-Pulled Noodles with Beef and other characteristic food industries. 
3) Modern industrial clusters with outstanding development advantages:

It's needed to rely on superior resources to build an important energy base in the country. Around LanzhouXining Economic Zone, Guan-Tian Economic Zone, energy, non-ferrous metallurgy and new material bases, important petrochemical and energy reserve bases and transit hubs in the western region, important equipment manufacturing bases and biomedicine industrial bases. At the same time, it will build an important non-ferrous metallurgy industry base in the west, an important basic scientific research and development and production base for new materials, new energy, and space technology and so on.

It's needed to build a regional modern service industry that opens to the west. It is necessary to build a modern industrial system in an all-round way; vigorously develop modern service industries, speed up the construction of a platform for opening up to the outside world; make every effort to promote the construction of regional industry and finance centers, and make every effort to promote the construction of regional cultural tourism centers.

\section{REFERENCES}

[1] Lewis W A, "Economic development with Unlimited Supplies of Labor". The Manchester School, 1954, 22 (2).

[2] Deng Baisheng: the impact of Industrial structure changes on Economic growth in large countries: a Comparative Analysis of China and the United States in 1990 / 2010, Journal of Xiangtan University, No. 5, 2013

[3] Zhao Ruyu. Thoughts on the Theory of Industrial structure [J]. Tax and economy, 2003, 6 (15): 111 .

[4] Yang Zhanfeng, Duan Xiaomei. The effect of Industrial structure change on the quality of Economic growth-an Analysis based on the contribution of Total Factor Productivity in Chengdu-Chongqing Economic Zone [J]. Regional Research and Development, 2019, 38 (01): 3944

[5] Parrinello, Sergio. Service Economy Revisited [J]. Structural Change and Economic Dynamics, 2004 (15).

[6] Desmet K, Rossi-Hansberg E. Spatial Development [J]. American Economic Review, 2014104 (4): 12111243.

[7] Zhang Cuiju, Zhang Zongyi. Spatial econometric analysis of the factors affecting the upgrading of provincial industrial structure in China [J]. Statistical study, 2015, 32 (10): 32. 37

[8] Tian G J, Liu J Y, Zhang Z X. Urban functional structure characteristics and transformation in China [J] .Cities, 2002,19 (4): 243248

[9] Brandt L, Zhu X D. Accounting for China's Growth (IZA Discussion Paper No.4764) [R]. Bonn: IZA, 2010.

[10] Dekle R, Vandenbroucke G. A Quantitative Analysis of China's Structural Transformation [J] .Journal of Economic Dynamics \& Control,2012,36 (1): 119135.

[11] Chen Qiang. Research on Industrial Transformation and upgrading in Jilin City [D]. Jilin University, 2018.

[12] Peneder M. Industrial Structure and Aggregate Growth [J]. Structural Change and Economic Dynamics, 2003 (14): 427 / 448.

[13] Zhou X Y, Zhang J, LI J P. Industrial structural transformation and carbon dioxide emissions in China [J]. Energy Policy, 2013, 57 (6): 4351.

[14] Kao Ai-hsiung, Dang Min. Analysis of Industrial structure and Economic efficiency in China [J]. Commercial Age, 2011 (5): 119 to 120.
[15] Li Cun $\mathrm{Pu}$, he Jing. The nonlinear influence of Industrial structure upgrading on Economic growth and unemployment [J]. Statistics and decision-making, 2018, 34 (22): 150-153.

[16] Yuan, Li Guoping. The impact of Industrial relevance on the level of Economic Development: an Analysis based on EU input-output data [J]. Economic Geography, 2016, 36 (11): 7682.

[17] Jiao Yao. Study on the structural Adjustment of leading Industries in Anhui Province [D]. Anhui University, 2018.

[18] Wang Qiong. Research on Industrial relevance Measurement and leading Industry selection in Gansu Province [D]. Lanzhou University, 2015 .

[19] Gu Allen, Lu Zhiqiang. The impact of Economic structure change on China's carbon emissions: an Analysis based on IO-SDA method [J] Population, Resources and Environment in China. 2016 (03): 3745.

[20] Wang Miao, Ma Zhong, Hui Xiang. Evaluation of Water Resources Management based on SDA method-A case study of Zhangye City in Heihe River Basin [J]. Management Review, 2018, 30 (05): 158.

[21] Zhang Najun, Cheng Yutai. Study on algorithm comparison and Application of carbon Emission SDA Model [J]. Statistics and Information Forum, 2018, 33 (04): 6774

[22] Chen Xi, Xi Qiangmin, Li Guoping. An empirical study on the relationship between Industrial correlation and Spatial Distribution in Manufacturing Industry [J]. Geographical Studies, 2015, 34 (10) 1943-1956.

[23] Yu Chunjiao, Zheng Guangfeng. Analysis on the Interactive Development degree of producer Service Industry and Manufacturing Industry in Hubei Province [J]. Economic Geography, 2010, 30 (11): 1859-1864.

[24] Zhou Ting, enemy road, Zhu Chuangeng, et al. Analysis on Spatial characteristics of Industrial Relations in Huaihai Economic Zone [J] Geoscience, 2010, 30 (6): 854-859.

[25] Dong Qi, Zhang Jingxiang, Hu Yi, et al. The formation Mechanism of "Metropolitan Shadow area" based on Industrial Spatial connection

[26] Zhang Lei, Shen Yuming, Liu Kun. The Development of produce Services and the Promotion of Urban Economic function in Beijing [J]. Advances in Geographic Sciences, 2013, 32 (12): 1825-1834.

[27] Research Group of China input-output Society, Xu Xianchun, Q Shuchang, Yang Cuihong, Zhao Tonglu. Analysis of Industrial Relational degree in China-one of a series of analysis reports on input-output table in 2002 [J]. Statistical study, 2006 (11): 3-8. 